\title{
PRIMARY SPASTIC PARALYSIS AND PSEUDO- HYPERTROPHIC PARALYSIS IN DIFFERENT MEMBERS OF THE SAME FAMILY, WITH PROBABLE HEREDITY IN BOTH.
}

BY R. W. PHILIP, M.A., M.B.

Assistant to the Profebsor of Practice of Physic, University of Edinburgh.

THE following cases form a family group of considerable interest and importance. For the opportunity of studying them I am indebted to the kindness of Professor Grainger Stewart, under whose charge they have lately been, in the Royal Infirmary, Edinburgh.

The group consists of a father, G. P. sen., and two sons, A. P. and G.P. jun. As the family history is common property, I shall, before describing the individual cases, narrate so much of this as seems important, The father of G. P. sen. died about the age of sixty, of apoplexy, and the mother, aged fifty, from gradually advancing debility. Of this marriage, there were nine children, three daughters and five sons, beside the patient. Of all these the history is good. Uncles and aunts on both sides were numerous, and are reported to have been strong and healthy. G. F. sen. married thirty-two years ago, and his wife is alive and strong, aged fifty-three. The wife's family history is less perfect. A female consin, aged fifty, has been so completely paralysed, as to be unable to feed herself for eighteen years, while an uncle, aged sixty-six, has been similarly paralysed for a number of years. By this marriage also there were nine children, whose individual history is of interest :- (1) girl, drowned accidentally, aged seven; (2) girl, alive and healthy, aged twentyeight; (3) boy. died, aged fifteen, apparently of pseudo-hypertrophic paralysis. The father says that "for several years he hadn't the use of himself;" (4) boy, died aged eleven, with symptoms of dropsy; (5) girl, died, aged four, of scarlatina; (6) boy, alive and healthy, aged eighteen; (7) boy, died, aged fifteen, of pseudo-hypertrophic paralysis. His case was de- 
scribed as such by Dr. Macphail, Whifflet, ${ }^{1}$ (8) boy, A. P. (vide infra); (9) boy, G. P. jun. (infra).

Of the three at present in hospital,-

G. P. senior, aged sixty. was admitted on account of inability to walk properly. He has worked as a miner since he was little more than twenty, for the first twenty-five years among ironstone, latterly among coal. His occupation, besides taxing his strength much, involved continued working on his side, in cramped and constrained postures, often partially below water for hours. The space in which he worked not unfrequently measured from 2 feet to 2 feet 10 inches in height. Tivelve or thirteen years ago, he met with a severe accident. The guiding rope for the hutches or low waggons, used for carrying coal from the cutting to the bottom of the shaft, broke, and his clothes were entangled by the rapidly passing hutches. He was dragged for about 100 yards, being much squeezed, and sustaining severe injury to the right leg and hip. In consequence of this he was laid aside for twenty-six weeks. On recovering, he kept to coal-mining, as being lighter, though the position necessary for work was more cramped. At this time he began to experience a sensation of stiffness in the right lower limb, which made the bent posture difficult. He also noticed that when he put his foot to the ground, the whole limb began to shake. He occasionally suffered from darting pains, described as " burning," which passed up from the sole of the right foot to the loins. These gradually grew more constant and the general condition worse, till, two years ago, he had to give up work altogether, from inability to walk. In addition to the increased stiffiness and pain, his right foot tended to drag and trip easily. He had great difficulty in extending the leg at the knee and hip, and this difficulty made him walk on his toes. The tendency to trembling of the limb grew more marked. A year ago, the left leg showed signs of becoming similarly affected, and during the last two months he has felt a cold, aching pain in the upper arm, during movement. Three days ago he began to experience pains in the right shoulder, and the "startings," previously experienced in the leg, threaten to appear here also. The patient's home surroundings have been comfortable. He has always had good food. He frequently got tipsy on pay-nights. At other times he was sober. There is no history or suspicion of syphilis.

Present condition.-Patient is a man of 5 teet 9 inches, of fair development and muscularity. Scattered over his face and extremities are numerous pigmentation spots and cicatrices, the remains of injuries received from time to time in the course 
of his work. The lower part of the thorax projects abnormally, and is separated from the abdomen by a well-marked horizontal depression. A certain degree of lordosis is present.

In standing, he stoops a good deal, and supports himself entirely on the left leg, the right being flexed at the knee and hip, and forcibly adducted, so as to cross its fellow. The left leg is slightly bent at the knee and adducted. Talipes equinovarus is not marked. In walking, he makes use of a stick in his left hand, and in his right, a triangle stool of appearance like $\Delta$, the vertical side being held next himself, so as to afford a broad basis of support on the side towards which he tends to fall. As he lies in bed, the right thigh is flexed and adducted, and the right leg is flexed at the knee, the left to a less extent. The muscles of the right thigh, and the lower part of the abdominal muscles of the same side, show a high degree of contracture, while the calf muscles are flabby. On the left side, the muscles of the thigh, especially the hamstring and the adductors, feel rigid. Regulated movements of the lower limbs are practically abolished. The upper limbs show no lack of power of co-ordinated movement. Ankleclonus can sometimes be elicited, but the rigid condition of the parts considerably interferes with its demonstration, as also with the knee-phenomenon. Over other tendons, howerer, a slight tap produces exaggerated movement. This is specially well marked at the elbow. There is no important alteration in the organic reflexes, though the initiation of micturition is delayed. The superficial reflexes are normal. The affected muscles exhibit a diminished reaction to faradic stimulations. The reaction to galvanisation is generally lessened, but the right hamstrings exhibit increased irritability, being also abnormally sensitive to mechanical stimulation. There are no qualitative changes. An aching pain and a sensation of stiffness is experienced in the right knee, thigh, hip and groin, and occasionally in the shoulder und neck towards the same side. Patient also describes a feeling of coldness and numbness which extends from the right foot to the corresponding thigh. Sensibility is unimpaired. The special senses are intact, with the exception of sight, which has been much less acute since the accident twelve years ago. There is no ophthalmoscopic change. Of trophic disturbances, besides the wasting of certain muscles there is to be noted the presence of a number of bald patches-true alopecia areata-scattered over the head, and of erythematous and scaly blotches about the feet. His memory is not good; and he is apt to make contradictory statements, so that the sifting of the history has been matter of difficulty. In other respects, the cerebral functions seem normal. Percussion over the spine reveals the presence 
of a fairly well-defined sensitive area extending from the 7 th to the 11th dorsal vertebra, and less distinctly as far as the sacrum. The other systems seem healthy.

A. P., aged thirteen, was admitted on account of loss of power in body generally. Up to six years of age, he seems to have been a strong, healthy child. When two years old, he is reported to have fallen from a high bed to the floor on his back, but according to the parents, this accident did not produce permanent injury. He began school at the age of five, but in the course of a year it was observed that he had difficulty in walking. He was easily tired, and tended to fall unaccountably. $\mathrm{He}$ was, therefore, removed from school, as the parents feared he might tumble into a canal along which he had to pass. His plunıp, healthy appearance remained unclisturbed, but it was noticed that his gait became awkward, his legs being swung round, and his body swaying from side to side. Complaint was made of pain in the small of the back. The weakness gradually advanced, the tendency to fall increased, the muscles of the trunk and arms becoming affected, so that when down, he had difficulty in raising himself. The parents, who, as the history shows, have had ample reason to become observant, state that all this time they were of opinion that a number of the muscles gradually increased in size, while others diminished. 'Three years ago, the movements at the shoulder' joint became much restricted. A year later, his legs absolutely refused to support the weight of his body, and he had to be constantly on a chair, bolstered up with pillows. His left arm was elevated by bending the head forward, taking tho finger tips between his teeth, and raising the head again. Within the last year, the back has become much weaker, with a marked convexity posteriorly, and he had to be strapped to a chair. For a number of weeks he has been confined to bed.

Present condition.-Patient is a healthy-looking boy, with contented expression. His face and the backs of his hands have a faint brownish tinge, as if sunburnt. His facial expression suggests a constantly full mouth, and the large tongue tends to protrude, but there is no trickling of saliva. The head appears heavy, and inclines forward, but its movements are natural. He has a well-marked goitre. The patient usually lies or half sits in bed, his back supported by pillows, most of his weight resting on the left buttock. The left leg is flexed, and lies on its outer aspect, with the foot and ankle passed underneath the right knee. The right leg is also flexed, and lies on its inner aspect. the knee overlapping the left ankle. The right foot is partially extended, and lies partly on its inner edge, and partly on the inner half of the sole. T'he pose of the arms suggests 
powerlessness, the upper arms lying closely applied to the side of the body, and the forearms resting on the thighs. The lower part of the thorax bulges considerably forwards, and a marked furrow exists between it and the full abdomen. From the third dorsal vertebra to the sacrum, the spinal column is curved backwards and to the right, the curve being greatest in the lowest part of the dorsal region. Patient cannot raise himself sufficiently to attempt standing, but he is still able slowly to bring his right hand to his head by the action of the trapezius and scapular muscles, and the muscles of the forearm attached to the lower end of the humerus. The left arm is quite helpless. Of the muscles, some are markedly increased in bulk, others reduced. The tongue is distinctly enlarged, and rolls about in a heavy, cumbrous fashion. The cheeks are relatively fuller and feel abnormally firm. This seems due to enlargement of the buccinators. The muscles of expression act sluggishly. The muscles forming the floor of the mouth are thickened. The latissimi dorsi are wasted. Both deltoids are full and firm in the lower half, but atrophied in the upper. The trapezius is wasted, especially of the left side. The inferior scapular muscles appear in fair condition. The right pectoral is atrophied, and the power is abolished, the left less so. Biceps is atrophied on both sides, brachialis anticus less so. Neither triceps is much altered. Supinators, pronators, flexors and extensors of forearm and hand are well represented, and power of movement seems natural, though sometimes there is loss of time in its initiation. The muscles of the band appear intact. In the lower extremities, the calves art remarkably enlarged, and the buttocks to a less extent. Both sets of gluteal muscles are hard and firm, but there is almost total loss of power. The flexors and adductors of the thighs are firm, but almost powerless. The quadriceps extensor is hard and full, especially on the right, but power is much reduced. The hamstrings are more natural in appearance and strength. Both sets of calf muscles are much increased in bulk. 'There is a slight degree of talipes equino-varus. The muscles on the front of the leg are fuller and rounder than normally. Extension of the foot is possible, but power of flexion is lost. Of the back, the muscles on the right side appear fuller and firmer, those on the left are flabby. Both the atrophied and the hypertrophied muscles react less readily than normally to faradic and galvanic stimulation. No qualitative changes were detected. To the hand, the skin over the enlarged muscles feels considerably warmer than that of the rest of the body, but careful examination with the surface thermometer rerealed no appreciable alteration. The organic reflexes seem fairly natural, though for the last few weeks there has been a 
tendency to incontinence of urine. Patellar tendon-reflex is abolished, and there is no ankle-clonus. The superficial reflexes are natural. There are no sensory disturbances. There is no tenderness of the spinal cord. The intelligence is good, speech and memory are natural. In other respects, the boy seems in good health. He eats and sleeps well.

G. P., junior, aged eleven, was admitted on account of weakness in legs, and awkwardness of gait. He was in regular attendance at school up to the date of admission. There is no history of accident. Four years ago his parents observed that he walked more stiffly than was natural, and that his knees appeared weak. He used to trip occasionally. Two years later, it was remarked that the left foot was no longer placed flat on the ground in walking, the heel being distinctly raised. ${ }^{1}$ This alteration grew more marked, and was followed in three or four months by similar appearances in the right foot. Both feet tended to drag, and stumbling became more frequent. $\mathrm{He}$ never complained of pain. He never showed the "waddling " gait of his brother, nor did he tend to fall down "all of a heap." His calves do not appear to the parents to have increased in size.

Present condition.-He is a strong-looking boy of 4 feet $9 \mathrm{f}$

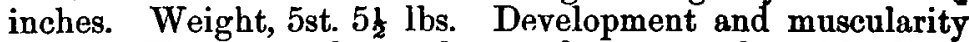
good. He runs about the ward, apparently with little difficulty. Close examination shows that he walks on his toes, his boots being accordingly altered in shape. This is most marked in the left foot. Both feet trip in walking, especially when the boy is tired. Both present the typical appearance of talipes equino-varus. The calf muscles are not enlarged, but feel firm. The tendo Achillis of both sides, of the left most markedly, is tense. The other muscles of the body seem natural. The organic reflexes are undisturbed. All the superficial reflexes are elicited with ease. The patellar tendon-reflexes and those of other tendons are exaggerated. Ankle-clonus is pronounced on both sides. Sensory functions are normal. The muscles of the left calf exhibit a diminished reaction both to faradic and galvanic stimulation. The muscles on the front of the same leg appear more excitable than is normal; and in the case of the tibialis anticus and long extensors of the toes, there is evidence of qualitative change. Bald patches, like those found on the father's, are present on the boy's head; and the dorsal aspect of the patient's toes are reddened, and present the appearance of

'The parents' observations are of considerable value, as long experience of disease had led them to watch the early development of symptoms with care. 
chilblains. There is no cerebral disturbance. The. spine is free of obvious deformity, and there is no tenderness or hyperæsthesia. The other systems are normal.

Remarks.-The cases are of interest as illustrating the occasional occurrence of different types of nervous disease in one family. That of G. P. (senior) is presumably one of gradually advancing spastic paralysis, probably excited by injury in a constitution predisposed to such affection through the previous ill-conditions of life. This view is supported by the history of the onset and the mode of advance,-the gradual increasing motor weakness, with rigidity of the lower extremities, and the comparative absence, from the beginning, of sensory disturbance. The exact significance of the sensory area, which apparently now exists at the lower part of the spinal column, is a question of some difficulty, but the presence of the area does not materially militate against the view that has been adopted. In addition to the spastic phenomena, his nervous system affords evidence of depreciation in the alopecic patches and other trophic disturbances. G. P. junior presents the early symptoms of a similar affection. The history and general characters, coupled with the exaggerated deep reflexes and ankle-clonus, are in favour of this view. The evidence of qualitative change in a single group of muscles was slight, and is insufficient to warrant dubiety with regard to the diagnosis, being, of course, capable of more than one explanation in harmony with this. Curiously enough, he, too, has bald patches on his head, closely resembling those seen in the father.

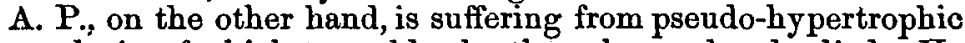
paralysis, of which two older brothers have already died. $\mathrm{H}_{\theta}$ has no alopecic patches. The facts, therefore, suggest a transmitted tendency to primary lateral sclerosis, while the family history illustrates the known hereditary character of pseudohypertrophic paralysis; the former apparently passing in the direct line from father to son, the latter, as usual, through the mother to the male children only (see history). A further interesting question in heredity arises, in view of the fact that, of all the children, only the youngest son-born after the father's spastic symptoms had begun to develop-became affected in this special way, and this, apparently, in the absence of a direct, exciting cause.

In connection with the case of pseudo-hypertrophic paralysis, there are one or two other points of interest. 'The increased heat of the skin over the affected muscles speaks in favour of the view, that the seat of disturbance is the vaso-motor system. This receives important confirmation in the presence of the 
well-marked goitre, without any indication of cretinism. Another curious fact is the presence of distinct pigmentation of the forehead and temples and backs of hands in a boy, who for months has practically been confined to the couch, recalling Dr. Gower's ${ }^{1}$ case of pseudo-hypertrophic paralysis, seen along with Sir Wm. Jenner, where the skin of the temples, posterior axillary fold, abdomen, back and thighs, was so pigmented as to warrant the diagnosis of Addison's disease, The last point is the tendency to incontinence of urine, which, during the last few weeks, has begun to manifest itself-a late symptom to which reference has been made by Dr Byrom Bramwell. ${ }^{2}$

' Gower's 'Pesendo-hypertrophic Paralysis,' p. 19, case 24.

2 'Lancet,' Aug. 9, 1879. 